\title{
Ginsenosides reduce body weight and ameliorate hepatic steatosis in high fat diet-induced obese mice via endoplasmic reticulum stress and p-STAT3/STAT3 signaling
}

\author{
YIN YAO ${ }^{1,2}$ \\ ${ }^{1}$ Department of Traditional Chinese Medicine Chemistry, School of Pharmacy, \\ Shanghai University of Traditional Chinese Medicine, Shanghai 200000; ${ }^{2}$ Department of Pharmacy, \\ Fourth People's Hospital of Gui Yang, Guiyang, Guizhou 550000, P.R. China
}

Received February 20, 2019; Accepted October 24, 2019

DOI: $10.3892 / \mathrm{mmr} .2020 .10935$

\begin{abstract}
Obesity has been increasing globally for over three decades. According to previous studies, dietary obesity is usually associated with endoplasmic reticulum stress (ERS) and STAT3 signaling, which result in interference with the homeostatic control of energy and lipid metabolism. Ginsenosides (GS) administered to mice will modulate adiposity and food intake; however, the mechanism of food inhibition is unknown. The aim of the present study was to investigate whether GS may inhibit ERS and regulate STAT3 phosphorylation in GT1-7 cells (a mouse hypothalamus gonadotropin-releasing hormone neuron cell line) and the hypothalamus in order to reduce the body weight and ameliorate hepatic steatosis in high fat diet (HFD)-induced obese mice. In the present study, GS inhibited the appetite, reduced the body weight, visceral fat, body fat content and blood glucose, and ameliorated the glucose tolerance of the obese mice compared with HFD mice. In addition, the levels of aspartate aminotransferase and alanine aminotransferase, triglyceride (TG), leptin and insulin in the serum were reduced compared with HFD mice. There was less TG in the liver, but more in the feces compared with HFD mice. Using hematoxylin and eosin staining of HepG2 cells and liver tissues, GS were demonstrated to improve the non-alcoholic fatty liver of the HFD-induced obese mice and reduce the diameter of the fat cells compared with HFD mice. GS also increased oxygen consumption and carbon dioxide emissions in the metabolic cage data compared with HFD mice. In the GT1-7 cells, GS alleviated the ERS induced by tunicamycin and enhanced the activation of the STAT3
\end{abstract}

Correspondence to: Dr Yin Yao, Department of Traditional Chinese Medicine Chemistry, School of Pharmacy, Shanghai University of Traditional Chinese Medicine, 1200 Cailun Road, Shanghai 200000, P.R. China

E-mail: yaoyin@vip.163.com

Key words: ginsenosides, high fat diet-fed mice, nonalcoholic fatty liver disease, GT1-7, STAT3, endoplasmic reticulum stress phosphorylation pathway. Furthermore the ERS of the liver was relieved to achieve the aforementioned pharmacological effects. GS were used in the homeostatic control of the energy and lipid metabolism of a diet-induced obesity model. In conclusion, present studies suggest that GS exert these effects by increasing STAT3 phosphorylation expression and reducing the ERS. Thus, GS reduce body weight and ameliorate hepatic steatosis in HFD-induced obese mice.

\section{Introduction}

The incidence of metabolic disorders and obesity has increased globally, and this has become a major health problem. Although $<5 \%$ of the global population live in America, $13 \%$ of the obese population globally reside there (1). Two-thirds of the obese population reside in developing countries, including China and India $(2,3)$. Obesity and nonalcoholic fatty liver disease (NAFLD) are not superficial diseases; they have become major risk factors for morbidity and mortality (4). For example, they increase the risk of type 2 diabetes and high blood pressure, and cause dyslipidemia, cardiovascular disease, hyperuricemia and obstructive sleep apnea-hypopnea syndrome (5).

Leptin, a type of protein hormone secreted by adipose tissue and skeletal muscle, may participate in the regulation of sugar, adipose and energy metabolism (6). Free leptin, its active form, binds to specific transport proteins, which are transmitted via signal transduction and STAT3 pathways $(7,8)$. The phosphorylation of STAT3 results in a reduction in ingestion, increased energy release and inhibition of the synthesis of adipose cells, which results in an overall reduction in weight (9). Leptin is then cleared by the kidneys (10).

In the endoplasmic reticulum stress (ERS) of eukaryotic cells, unfolded or misfolded proteins accumulate and trigger the unfolded protein response (UPR) (11). The UPR is an indicator of ERS and is mediated by three important ERS receptor proteins: Double stranded RNA-dependent protein kinase-like endoplasmic reticulum kinases (PERKs), inositol requiring enzyme 1 (IRE) and activating transcription factor $6 c$ (ATF6) (12). In the resting state, the three types of transmembrane protein and glucose regulation protein 78 (GRP78) binding immunoglobulin protein are in the inactive state (13). 
Numerous studies have demonstrated that chronic overeating may result in tissue ERS, insulin resistance and inflammation in adipose tissue in ob/ob mice and high-fat diet (HFD)-fed mice $(14,15)$.

NAFLD refers to the clinicopathologic syndrome characterized by excessive fat deposition in hepatocytes caused by alcohol exclusion and other definite hepatogenic factors (16). A large quantity of free fatty acids (FFAs) accumulate in hepatocytes, inducing lipid peroxidation in hepatocytes and eventually the apoptosis and necrosis of cells. In this process, strong lipid peroxidation is the inducing factor of ERS (17). ERS is conducive to the homeostasis of hepatocytes (18). However, due to the excessive accumulation of lipids and persistent lipid peroxidation reaction, the ERS response lasts too long and is too strong, which causes cellular damage (19). A previous study revealed that mice without ATF6- $\alpha$, eukaryotic initiation factor $2 \alpha$ (eIF2- $\alpha$ ) and IRE1- $\alpha$ in the ERS pathway, exhibited ERS disorder and hepatic steatosis, suggesting that ERS may be involved in the cause of fatty liver disease (20).

Ginsenosides (GS) [Chemical Abstracts Service (CAS) no. 90045-38-8] are an extract from the roots, stems and leaves of ginseng (21). It is a yellow-white or light yellow amorphous powder that has a slight smelly odor and is bitter and hygroscopic (22). GS have various pharmacological effects on the human body (23). In the cardiovascular system, GS reduce arrhythmia, cardiac hypertrophy, myocardial ischemia and myocardial cell apoptosis (24). In terms of a tumor, GS may induce apoptosis, inhibit tumor cell proliferation and regulate signal pathways and immune functions (25). With regards to metabolic regulation, GS inhibit feeding behavior through the ventromedial hypothalamic nucleus, and inhibit the absorption of fatty foods in the intestinal tract by reducing the activity of pancreatic lipase (PL) or through regulation of the lipogenic transcription factor-peroxidase proliferator activation receptor (PPAR) (26,27). Glucolipid metabolism regulates the expression of adenosine activated protein kinase (AMPK) and its target genes (28). However, the mechanism by which GS reduces dietary intake is unknown. In a previous study, GS were revealed to exert a significant effect on reducing the food intake and weight of HFD-induced obese mice, significantly reducing serum triglycerides (TGs; $\mathrm{P}=0.03$ ), increasing glucose tolerance, improving insulin resistance and reducing the degree of obesity in mice, compared with HFD mice (29). A further study demonstrated that GS significantly inhibited the transcriptional activity of C/EBP homologous protein (CHOP; $\mathrm{P}=0.028)$ and GRP7 $(\mathrm{P}=0.04)$ compared with HFD mice, indicating that GS reduce ERS (30). Therefore, the present study hypothesized that GS may alleviate ERS and thus increase the sensitivity of the leptin receptor in order to inhibit obesity.

\section{Materials and methods}

Compounds. GS (CAS no. 90045-38-8; cat. no. PS010497) were purchased from Chengdu Push Bio-Technology Co., Ltd. According to the product specification, the extract is mainly composed of saponins (total content, $>80 \%$ ). The GS were dissolved in dimethylsulfoxide (DMSO; Sigma-Aldrich; Merck KGaA) for in vitro studies. Tunicamycin (TM; CAS no. 11089-65-9; cat. no. T7765) was obtained from Sigma-Aldrich (Merck KGaA) in order to induce ERS.
Animals and diet. The present study was conducted in accordance with the ethical standards and according to the Ethical Committee of Shanghai University of Traditional Chinese Medicine (Shanghai, China). The protocols were ethnically approved by the Institutional Animal Care and Use Committee of Shanghai University of Traditional Chinese Medicine (approval no. SZY201708002).

Male C57BL/6 mice ( $n=15$; weight, 15-20 g) were purchased from Shanghai Laboratory Animal Center, certificate no. 20080016722050; Shanghai, China) at 4 weeks of age. The mice were individually housed under a $12 \mathrm{~h}$ light-dark cycle at $22-23^{\circ} \mathrm{C}$, with access to a standard chow diet and distilled water ad libitum during the adaptation week. Subsequently, the mice were placed on a HFD $(60 \%$ of calories derived from fat, $5.24 \mathrm{Kcal} / \mathrm{gm}$; cat. no. D12492; Research Diets, Inc.) for 3 months to induce obesity (31). The HFD-fed mice were distributed into two groups of five mice and housed in cages to permit control of their food intake and body weight. All mice in these two groups continued to receive a HFD. A separate group of mice $(n=5)$ were fed a standard chow diet $(10 \%$ of calories derived from fat; cat. no. D12450B; Research Diets, Inc.) as a control group.

The C57BL/6 were fed either a standard chow diet (CHOW group; $n=5$ ) or a HFD (HFD group; $n=5$ ) for 3 months. The HFD-fed mice were treated with either GS at $120 \mathrm{mg} / \mathrm{kg}$ / day (HFD+GS group; $n=5$ ) or with the vehicle (HFD group; $n=5$ ) for the final 28 days of the study period.

Cell culture. HepG2 and GT1-7 cell lines (American Type Culture Collection) were cultured in DMEM (Biological Industries) supplemented with 10\% FBS (Thermo Fisher Scientific, Inc.) and $1 \%$ penicillin/streptomycin solution (Thermo Fisher Scientific, Inc.). The GT1-7 cells were incubated in a fully humidified $5 \% \mathrm{CO}_{2}$ incubator at $37^{\circ} \mathrm{C}$. The medium was changed every 2-3 days, and the cells were routinely passaged every 6-8 days. Briefly, for the ERS group, the cells were seeded at a density of $2 \times 10^{5}$ cells per well in 6-well plates. The first well contained no treatment (control). From the second to the sixth wells, $5 \mu \mathrm{g} / \mathrm{ml} \mathrm{TM}, 5 \mu \mathrm{g} / \mathrm{ml} \mathrm{TM}$ $+25 \mu \mathrm{g} \mathrm{GS}, 5 \mu \mathrm{g} / \mathrm{ml} \mathrm{TM}+50 \mu \mathrm{g} \mathrm{GS}, 5 \mu \mathrm{g} / \mathrm{ml} \mathrm{TM}+100 \mu \mathrm{g}$ GS and $5 \mu \mathrm{g} / \mathrm{ml} \mathrm{TM}+200 \mu \mathrm{g}$ GS were added, respectively, subsequent to incubation at $37^{\circ} \mathrm{C}$ for $24 \mathrm{~h}$ to analyze the presence of ERS through the expression levels of GRP78, CHOP, phosphorylated (p)-PERK, PERK and activating transcription factor 4 (ATF4). For the phosphorylated p-STAT3/STAT3 group, the cells were seeded at a density of $2 \times 10^{5}$ cells per well in 6-well plates. The first well contained no treatment (control). From the second to the sixth wells, GS (12.5, 25, 50, 100 and $200 \mu \mathrm{g}$ ) were added, respectively, and the cells were incubated at $37^{\circ} \mathrm{C}$ for $24 \mathrm{~h}$ to extract the protein to measure the p-STAT3/STAT3 ratio (32).

Preparation of FFAs. A hepatocyte steatosis model was established using complete medium containing oleic acid (OA; Sigma-Aldrich; Merck KGaA) and palmitic acid (PA; Sigma-Aldrich; Merck KGaA) and the efficacy was evaluated using oil red $\mathrm{O}$ staining. DMEM medium with $10 \% \mathrm{FBS}$ containing $200 \mathrm{M} \mathrm{OA}$ and $100 \mathrm{M}$ PA was used. Initially, the palmitic acid was saponified with sodium hydroxide solution and turned into sodium palmitate to prepare the solution. At 
a normal temperature water-soluble OA and PA sodium was low, so they were dissolved in a $75^{\circ} \mathrm{C}$ water bath for $10 \mathrm{~min}$. Then, 20 and 40\% degreased bovine serum albumin (BSA; Sigma-Aldrich; Merck KGaA) solutions were prepared, and the BSA was completely dissolved using centrifugation at $5,255 \mathrm{x} \mathrm{g}$ for $15 \mathrm{~min}$ at room temperature. Completely dissolved OA or PA sodium solution, respectively, was mixed with $20 \%$ BSA or $40 \%$ BSA solution, and then run through a $0.22 \mu \mathrm{m}$ filter subsequent to eliminating bacteria, and stored at $4^{\circ} \mathrm{C}$ in a refrigerator.

Western blotting. Following the treatments listed above, $2 \times 10^{5}$ cells/well were lysed using RIPA lysis buffer (Beyotime Institute of Biotechnology) containing a protease inhibitor cocktail (Beyotime Institute of Biotechnology). A BCA assay kit was used for protein concentration determination (Beyotime Institute of Biotechnology) and either 20 or $80 \mu \mathrm{g}$ protein, to measure ERS or the p-STAT/STAT3 ratio, respectively, was mixed with $2 \mathrm{X}$ SDS-PAGE sample buffer $(25 \%$ SDS, $62.5 \mathrm{mM}$ Tris- $\mathrm{HCl}, \mathrm{pH}$ 6.8, 25\% glycerol, 0.5 M DTT and $0.1 \%$ Bromophenol Blue) and then boiled for $7 \mathrm{~min}$ at $99^{\circ} \mathrm{C}$. Proteins were separated by $12 \%$ SDS-PAGE and then transferred to a PVDF membrane (EMD Millipore). The membranes were blocked with 5\% BSA (Gibco; Thermo Fisher Scientific, Inc.) for $2 \mathrm{~h}$ at room temperature. Subsequently, the membranes were incubated with primary antibodies against GRP78, CHOP, p-PERK, PERK, ATF4 and $\beta$-actin for $4^{\circ} \mathrm{C}$ for $12 \mathrm{~h}$ to assess ERS, whereas primary antibodies against p-STAT3, STAT3 and $\beta$-actin were incubated at $4^{\circ} \mathrm{C}$ for $24 \mathrm{~h}$ to obtain the p-STAT3/STAT3 ratio. Following the primary antibody incubation, membranes were incubated with an IR-Dye ${ }^{\mathrm{TM}}$-700/800-labeled fluorescent secondary antibody (LI-COR Biosciences) for $1 \mathrm{~h}$ at room temperature in the dark. Finally, proteins were visualized using the LI-COR Odyssey infrared imaging system (LI-COR Biosciences) and expression levels were quantified using Image-Pro Plus version 6.0 software (Media Cybernetics, Inc.).

For the tissue-based assays, at the end of the treatment, overnight fasting blood samples were withdrawn by cardiac puncture following anesthesia (urethane, $2 \mathrm{~g} / \mathrm{kg}$, intraperitoneal). Whether the mice were in a coma was determined using the following three criteria: i) The depth of anesthesia in mice was determined by pinching the toes with forceps; ii) the normal respiratory rate of the mice should be 180 times per min, and when anesthetized, the respiratory rate should decrease proportional to the depth of the anesthesia, but the mice should remain breathing; and iii) the mucous membranes of the mice must remain pink, not blue or gray. Subsequent to extracting the tissue and blood, the mice were placed into a sealed box and euthanized (filled with $\mathrm{CO}_{2}, 30 \%$ per min, 1-3 min). When all the mice had succumbed to mortality (determined by observing the respiratory rate of the mice and the color change of the mucous membrane), they were registered (species, sex, number, etc.) and handed over to a professional for disposal. The liver and hypothalamus tissues of the mice in each group were homogenized using RIPA buffer containing protease inhibitor cocktail and phosphatase inhibitor cocktails (Beyotime Institute of Biotechnology) using a hand-held motor and maintained on ice for $1 \mathrm{~h}$ to lyse the cells completely. The homogenates were then centrifuged at $12,000 \mathrm{x} \mathrm{g}$ for $30 \mathrm{~min}$ at $4^{\circ} \mathrm{C}$. The supernatants were collected, and protein concentration was determined using BCA protein assay kit, and then boiled for $10 \mathrm{~min}$ at $99^{\circ} \mathrm{C}$. The remaining steps are consistent with the cell western blotting protocol.

Antibodies against p-STAT3 (1:500; cat. no. CST9134) and STAT3 (1:1,000; cat. no. CST9139) were obtained from Cell Signaling Technology, Inc. Antibodies against CHOP (1:1,000; cat. no. 15204-1-AP), ATF4 (1:1,000; cat. no. 24169-1-AP), PERK (1:1,000; cat. no. 20582-1-AP) and $\beta$-actin $(1: 1,000$; cat. no. 66009-1-lg) were purchased from ProteinTech Group, Inc. Antibodies against GRP78 (1:500; cat. no. 35394) and p-PERK (1:500; cat. no. 12379) were purchased from Signalway Antibody LLC. The IR-Dye ${ }^{\mathrm{TM}}-700 / 800$-labeled fluorescent secondary antibody (1:10,000; cat. no. 042-07-18-06) was purchased from LI-COR Biosciences.

Administration of GS. Intraperitoneal injections were performed in the daytime. The mice were acclimatized for 28 days by daily intraperitoneal injections of vehicle (DMSO+ normal saline; NS) prior to the start of GS injections. GS $(120 \mathrm{mg} / \mathrm{kg} / \mathrm{mice})$ were dissolved in DMSO $(10 \mu \mathrm{l})+\mathrm{NS}(40 \mu \mathrm{l})$ and administered to the mice intraperitoneally once a day. The corresponding vehicle groups were injected intraperitoneally with a total volume of $50 \mu 1 \mathrm{DMSO}+\mathrm{NS}$ once a day. The daily food intake was calculated as the mean food intake per day during the four weeks of treatment.

Intraperitoneal glucose and insulin tolerance tests. For the glucose tolerance test, the C57BL/6 mice were fasted for $12 \mathrm{~h}$ and the basal blood glucose levels ( $0 \mathrm{~min})$ were measured from the tail vein. Subsequently the mice were intraperitoneally injected with glucose $(1 \mathrm{~g} / \mathrm{kg}$ body weight) and the blood glucose levels were measured at 15, 30, 60 and $90 \mathrm{~min}$. For the insulin tolerance test, the mice were intraperitoneally injected with 0.75 U/kg insulin (cat. no. I-9278; Sigma-Aldrich; Merck $\mathrm{KGaA}$ ) without fasting. Prior to the injection of insulin, the blood samples were collected from the tail vein for measurement of basal blood glucose levels ( $0 \mathrm{~min})$, and the blood glucose levels were also measured at 15, 30,60 and $90 \mathrm{~min}$, as previously described (33).

Metabolic chamber measurements. Metabolic parameters of the mouse models (lean and diet-induced obesity) were determined using a Comprehensive Lab Animal Monitoring System (Columbus Instruments International). The following four parameters were tested: Oxygen consumption $\left(\mathrm{VO}_{2}\right)$, carbon dioxide consumption $\left(\mathrm{VCO}_{2}\right)$, respiratory exchange ratio (RER) and ambulatory activity (X-Amb) (34).

Magnetic resonance imaging (MRI). The mice were examined in an MRI scanner (EchoMRI ${ }^{\mathrm{TM}}-500$; EchoMRI LLC) in a prostrate position, using a whole-body coil and a two-point Dixon sequence. The mice were fixed in plastic cylindrical barrels to reduce their movement. The remaining operations were conducted according to the manufacturer's protocol.

Hematoxylin and eosin $(H \& E)$ and oil red $O$ staining. For $H \& \mathrm{E}$ staining, the liver tissue was fixed with $10 \%$ formaldehyde for $24 \mathrm{~h}$ at $4^{\circ} \mathrm{C}$, embedded in paraffin and cut into $10 \mathrm{~mm}$ sections according to a standard protocol. The sections were stained with 
H\&E (hematoxylin, $10 \mathrm{~min}$; eosin, $30 \mathrm{sec}$; room temperature). The adipose tissue or frozen sections of liver were washed with phosphate buffered saline twice, fixed with $10 \%$ formalin at room temperature for $10 \mathrm{~min}$ and then stained with oil red $\mathrm{O}$ (Sigma-Aldrich; Merck KGaA) at $60^{\circ} \mathrm{C}$ for $10 \mathrm{~min}$. Subsequently, images were captured using a light microscope (magnification, x200 or x400; Nikon Corporation). Oil red O stained sections were evaluated using Image-ProPlus 6.0 software (Media Cybernetics, Inc.) and H\&E staining sections were evaluated according to The Pathology Committee of the NASH Clinical Research Network's histological feature scoring system (35).

Serum biochemistry analysis. Subsequent to overnight fasting for $12 \mathrm{~h}$, all mice were anesthetized with urethane $(2 \mathrm{~g} / \mathrm{kg}$, intraperitoneally) and then blood samples were collected for analysis. The blood samples were drawn from the apex cordis into an epoxy resin tube, and serum samples were separated from the blood. Serum TG, total cholesterol (TC), high-density lipoprotein cholesterol (HDL-c), low-density lipoprotein cholesterol (LDL-c) levels, alanine aminotransferase (ALT) and aspartate aminotransferase (AST) were measured using a Hitachi 7020 Automatic Analyzer (Hitachi, Ltd.).

Liver lipid content analysis. The liver, abdominal adipose, perirenal adipose and epididymis adipose were collected rapidly at the end of treatment, frozen in liquid nitrogen and stored at $-80^{\circ} \mathrm{C}$ for the following experiments. To assess the liver lipid content, $50 \mathrm{mg}$ frozen liver tissues were homogenized in $1 \mathrm{ml}$ lysis buffer (20 mM Tris- $\mathrm{HCl}, \mathrm{pH} 7.5,150 \mathrm{mM}$ $\mathrm{NaCl}$ and $1 \%$ Triton) and mixed with an equal volume of chloroform. The chloroform layer was separated, dried and resuspended in isopropyl alcohol to measure the lipid levels using a Triglycerid Reagent kit (cat. no. A0-10017) and a Total Cholesterol Reagent kit (cat. no. A010027; both Nanjing JianCheng Bioengineering Institute) according to the manufacturer's protocol.

Feces lipid content analysis. The feces were collected rapidly within three days prior to the end of the treatment, frozen in liquid nitrogen, and stored at $-80^{\circ} \mathrm{C}$ for the following experiments. To assess the feces lipid content, $100 \mathrm{mg}$ frozen feces were homogenized in $1 \mathrm{ml}$ lysis buffer (20 mM Tris-HCl, pH 7.5, $150 \mathrm{mM} \mathrm{NaCl}$ and $1 \%$ Triton) and mixed with an equal volume of chloroform. The chloroform layer was separated, dried and resuspended in isopropyl alcohol to measure the lipid levels using a using a Triglycerid Reagent kit (cat. no. A0-10017) and a Total Cholesterol Reagent kit (cat. no. A010027; both Nanjing JianCheng Bioengineering Institute) according to the manufacturer's protocol.

ELISA. The serum insulin and leptin levels were measured using an ELISA. The mouse serum was stored at $-80^{\circ} \mathrm{C}$ and incubated at $37^{\circ} \mathrm{C}$ for thawing prior to analysis. The kits for insulin (cat. no. 80-INSMSU-E01) and leptin (cat. no. 80-LEPMS-E01) were obtained from ALPCO. The enzyme levels in the supernatants were measured according the manufacturer's protocol.

Statistical analysis. All values are expressed as the mean \pm SEM. Data were analyzed using SPSS software (version 21.0; IBM Corp., Armonk, NY, USA). One-way ANOVA and Duncan's multiple range tests were used to determine the significance of differences between groups. $\mathrm{P}<0.05$ was considered to indicate a statistically significant difference.

\section{Results}

$G S$ administration reduces food intake and reverses the obesity and hyperleptinemia induced by HFD. To assess whether GS reduce diet-induced obesity, C5BL/6 mice were fed a HFD for 4 weeks and administered GS via an intraperitoneal injection every day $(120 \mathrm{mg} / \mathrm{kg} / \mathrm{day})$. The mice fed the HFD had an above mean body weight compared with the standard chow diet-fed mice subsequent to 4 weeks of treatment (Fig. 1A). The HFD+GS group, however, had a significantly reduced body weight in the mice compared with the HFD group (Fig. 1A and B; $\mathrm{P}<0.01$ ). Similarly, the food intake amount was significantly different between the HFD and HFD+GS group ( $\mathrm{P}<0.05$; Fig. 1C), implying that the lower body weight in the HFD+GS group resulted from a lower calorie intake. The diameter of fat cells may indirectly reflect lipid metabolism (36). Histological analysis demonstrated that the GS group significantly reduced the size of the white adipose tissue compared with the HFD group $(\mathrm{P}<0.01)$, implying that GS reduces adipocyte mass in HFD-fed mice (Fig. 1D and E). GS administration altered the lean mass of HFD-fed mice relative to the standard chow group (Fig. $1 \mathrm{~F}$ and $\mathrm{G} ; \mathrm{P}<0.05$ ). Also, the percentage fat of the bodyweight in the HFD+GS group were significantly less compared with that of standard chow diet-fed groups (Fig. $1 \mathrm{H}$ and $\mathrm{I} ; \mathrm{P}<0.01$ ). When the experiment was completed, the weight of visceral fat in the mice was measured. The data revealed that the liver weight, abdominal fat, epididymis fat and perirenal fat were significantly reduced in the HFD+GS group compared with the HFD group (Fig. 1J-M; P<0.01). These results suggested that GS may induce a suppressed appetite and lose the weight caused by a HFD in mice.

GS increase glucose tolerance, reduce insulin resistance and reduce blood leptin and insulin levels in HFD mice. A large number of studies have reported that HFD-fed mice demonstrate impaired glucose and insulin intolerance compared with standard chow-fed mice (37-40). In the present study, the HFD+GS group had a significantly improved fasting glucose level, glucose tolerance and insulin tolerance compared with the HFD group. (Fig. 2A and B; P<0.01). Similarly, leptin, an endocrine hormone secreted by adipose tissue, is present at significantly higher levels in HFD-fed mice compared with those in standard chow diet-fed mice (41). In order to examine whether the leptin levels were increased in HFD-fed mice in the present study, leptin contents were assessed using an ELISA. GS significantly reduced the leptin levels of the HFD-fed mice compared with the HFD group. (Fig. $2 \mathrm{C} ; \mathrm{P}<0.01$ ). Obesity is able to increase blood sugar, reduce glucose tolerance, raise insulin resistance and cause hyperinsulinemia and hyperleptinemia (42-44). In order to examine whether the insulin levels were increased in the HFD-fed mice, the insulin parameters were assessed using an ELISA. The results demonstrated that the insulin levels were increased significantly in the HFD-fed mice compared with the $\mathrm{CHOW}$ group $(\mathrm{P}<0.01)$. Furthermore, 
A

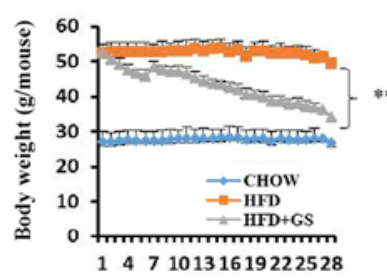

D
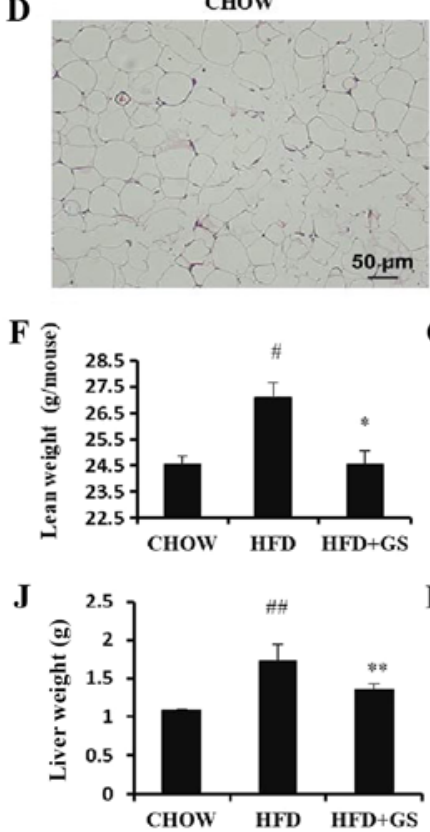

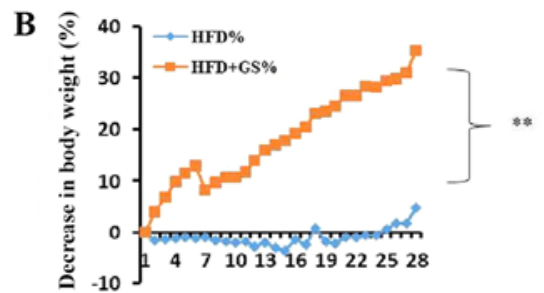

HFD
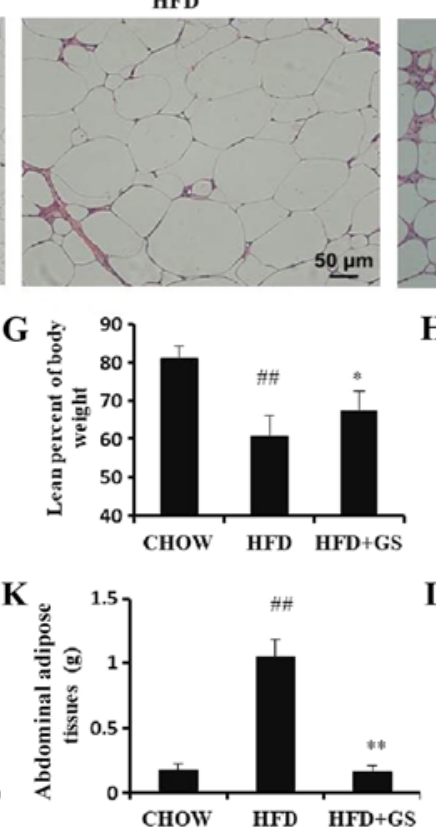

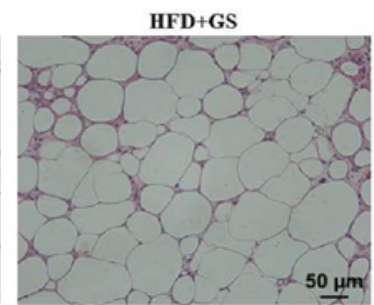

H
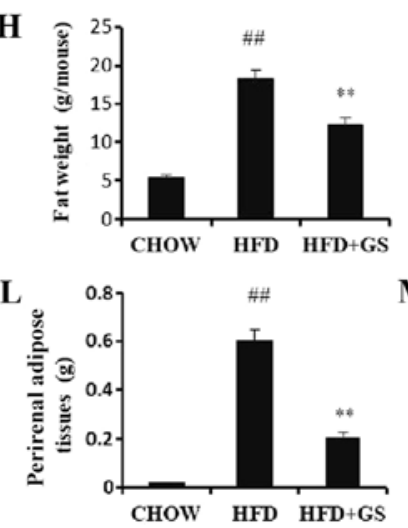

E
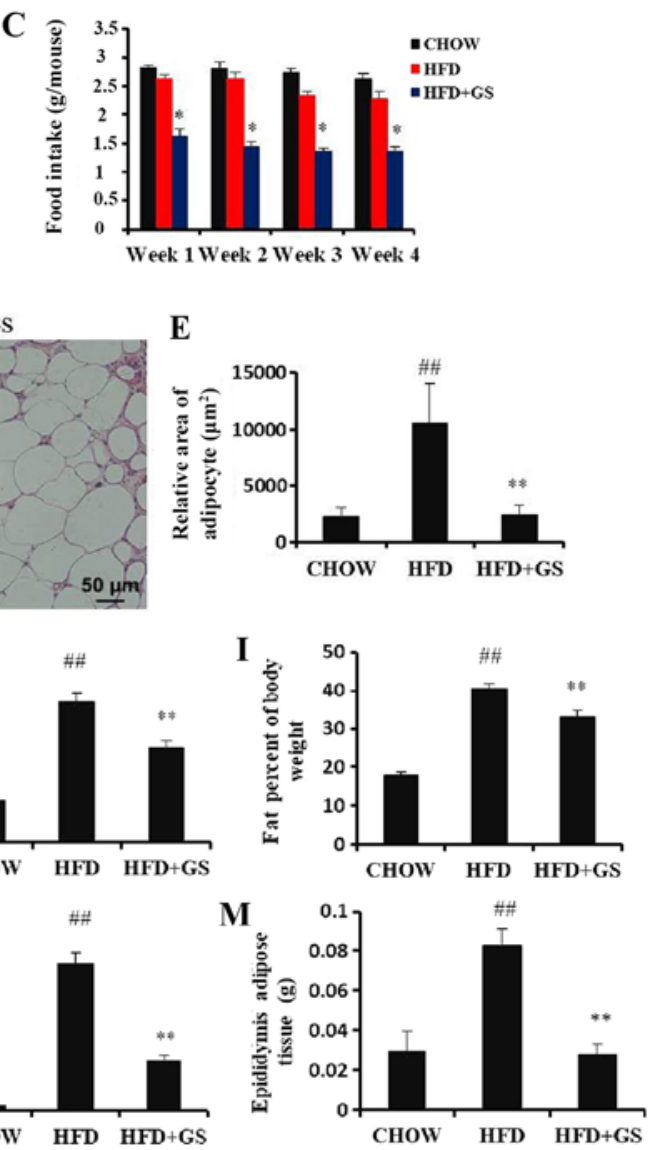

Figure 1. GS administration reduces food intake and reverses the obesity induced by a HFD. (A) Body weight $\mathrm{n}=5$ per group. (B) Percentage reduction in body weight. (C) Food intake of the HFD-fed mice during the four weeks of treatment. The mice were subjected to a 4-weeks treatment of standard chow, HFD or GS (120 mg/kg; daily, intraperitoneal injection). (D) Hemoxylin and eosin staining of the adipose tissue. (E) Relative area of the adipocytes. (F) Lean weight. (G) Lean percentage of body weight. (H) Fat weight. (I) Fat percentage of body weight. The HFD-fed mice were analyzed with by magnetic resonance imaging following 3 weeks of treatment. (J) Liver weight. (K) Abdominal, (L) perirenal and (M) epididymis adipose tissues. Error bars present the mean \pm standard error of the mean. P-values were determined by one-way ANOVA. ${ }^{*} \mathrm{P}<0.05$ and ${ }^{* *} \mathrm{P}<0.01$ vs. HFD group; ${ }^{\#} \mathrm{P}<0.05$ and ${ }^{\# \#} \mathrm{P}<0.01$ vs. CHOW group; $\mathrm{n}=5$ for all groups. GS, ginsenosides; HFD, high-fat diet; CHOW, mice administered a standard chow diet.

GS treatment significantly suppressed the insulin level, indicating that GS improved the hyperinsulinemia in the HFD-induce mice (Fig. 2D; $\mathrm{P}<0.01$ ).

GS improved the lipid metabolism of HFD mice. In order to determine the toxic effect of GS, the levels of ALT and AST in the blood were tested. The levels in the obese mice induced by a HFD-diet were significantly increased compared with standard chow-fed mice, while the AST and ALT levels were significantly decreased following GS treatment (Fig. 3A and B; $\mathrm{P}<0.01)$. The results revealed that GS exerted no toxicity to the liver at this dose. As expected for the HFD-fed mice, the serum TC, TG, LDL-c and HDL-c levels were significantly increased compared with the $\mathrm{CHOW}$ group (Fig. 3C-F; $\mathrm{P}<0.05$ or $\mathrm{P}<0.01)$. By contrast, the GS group exhibited significantly reduced serum TG levels compared with the HFD group (Fig. 3C; $\mathrm{P}<0.01$ ). GS treatment also significantly reduced serum TC and HDL-c levels compared with the HFD group (Fig. 3D and $\mathrm{E} ; \mathrm{P}<0.05$ ). However, no difference in the serum LDL-c levels were observed between the HFD + GS group and the HFD group (Fig. 3F). Subsequently, the TG levels in the liver and TC in the feces were tested. The levels of TG in the liver were significantly reduced in the HFD + GS group compared with the HFD group, whereas TC levels in the feces were significantly increased compared with the HFD group (Fig. 3G and $\mathrm{H} ; \mathrm{P}<0.05$ ).In summary, the results suggest that GS are not only non-toxic but may also alleviate lipid metabolic disorders.

GS alleviates lipid droplet accumulation in vivo and vitro. Excessive accumulation of TGs in cells is also a manifestation of the disorder of lipid metabolism in hepatocytes (45). A hepatocyte steatosis model was established using complete medium of OA and PA. The efficacy was evaluated using oil red $\mathrm{O}$ staining subsequent to drug intervention. In the present study, $24 \mathrm{~h}$ following the administration of GS, it was revealed that the oil red $\mathrm{O}$ inside the cells became lighter and the area decreased compared with the OA+PA well. This suggests that the mixture of OA and PA increased the lipid accumulation in HepG2 cells, while GS inhibited the lipid accumulation (Fig. 4A and $\mathrm{G} ; \mathrm{P}<0.05$ ).

Obesity develops into hepatic steatosis, primarily due to the destruction of the balance between fatty acid storage and mobilization $(46,47)$. In the present study, H\&E-stained liver sections revealed microvesicular and macrovesicular steatosis of the liver in the HFD-fed mice compared with the normal liver structure 

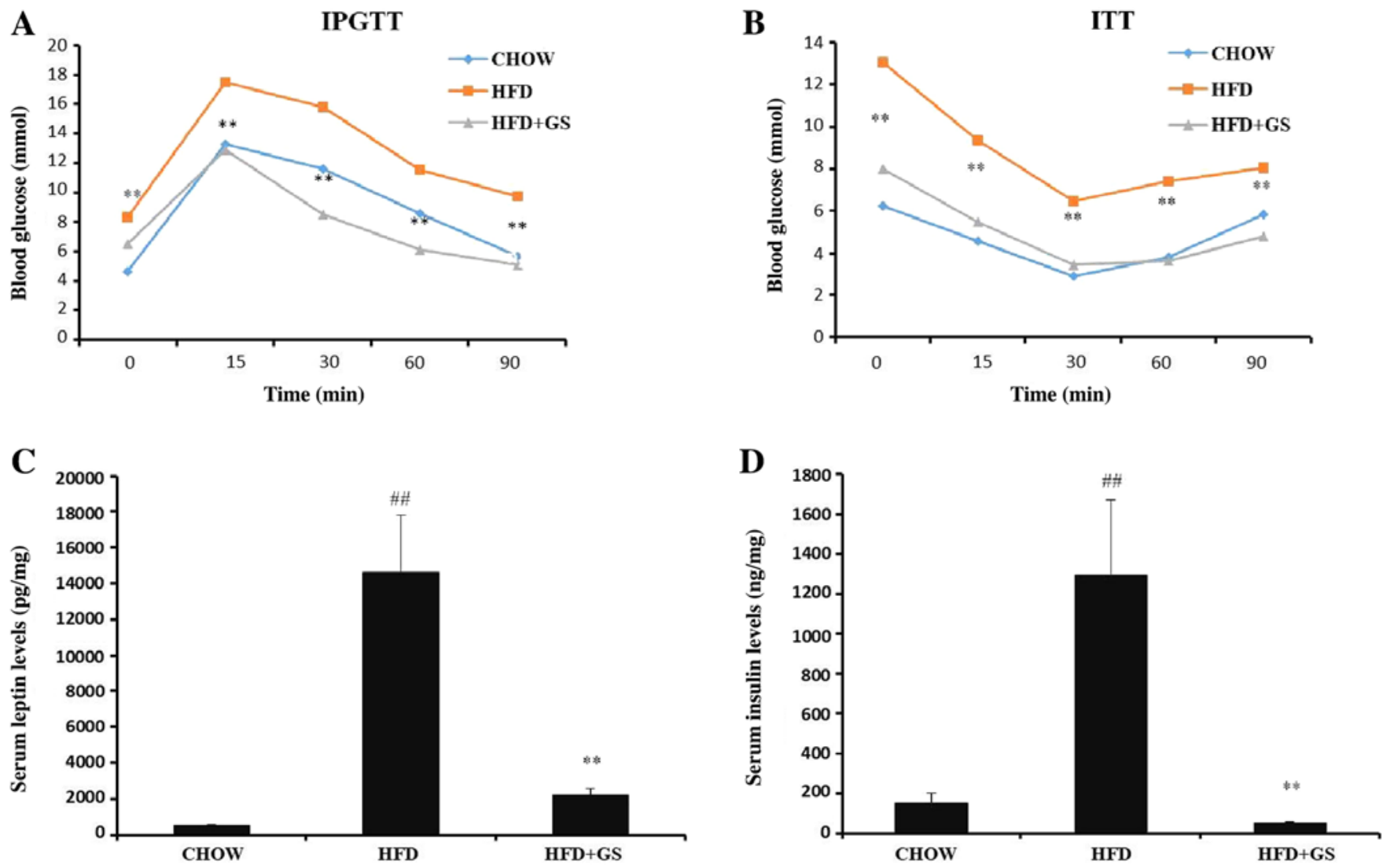

Figure 2. GS increases glucose tolerance, reduces insulin resistance and reduces blood leptin and insulin levels in HFD-fed mice. (A) Glucose tolerance test. The mice were fasted for $12 \mathrm{~h}$ and the tail vein blood was used to measure the blood glucose levels. (B) Insulin tolerance test. (C) Serum leptin. (D) Serum insulin. Error bars represent the mean \pm standard error of the mean. P-values were determined using one-way ANOVA. ${ }^{* *} \mathrm{P}<0.01$ vs. HFD group; ${ }^{\# \#} \mathrm{P}<0.01$ vs. CHOW group; $\mathrm{n}=5$ for all groups. GS, ginsenosides; HFD, high-fat diet; $\mathrm{CHOW}$, mice administered a standard chow diet; IPGTT, intraperitoneal glucose tolerance test; ITT, insulin tolerance test.
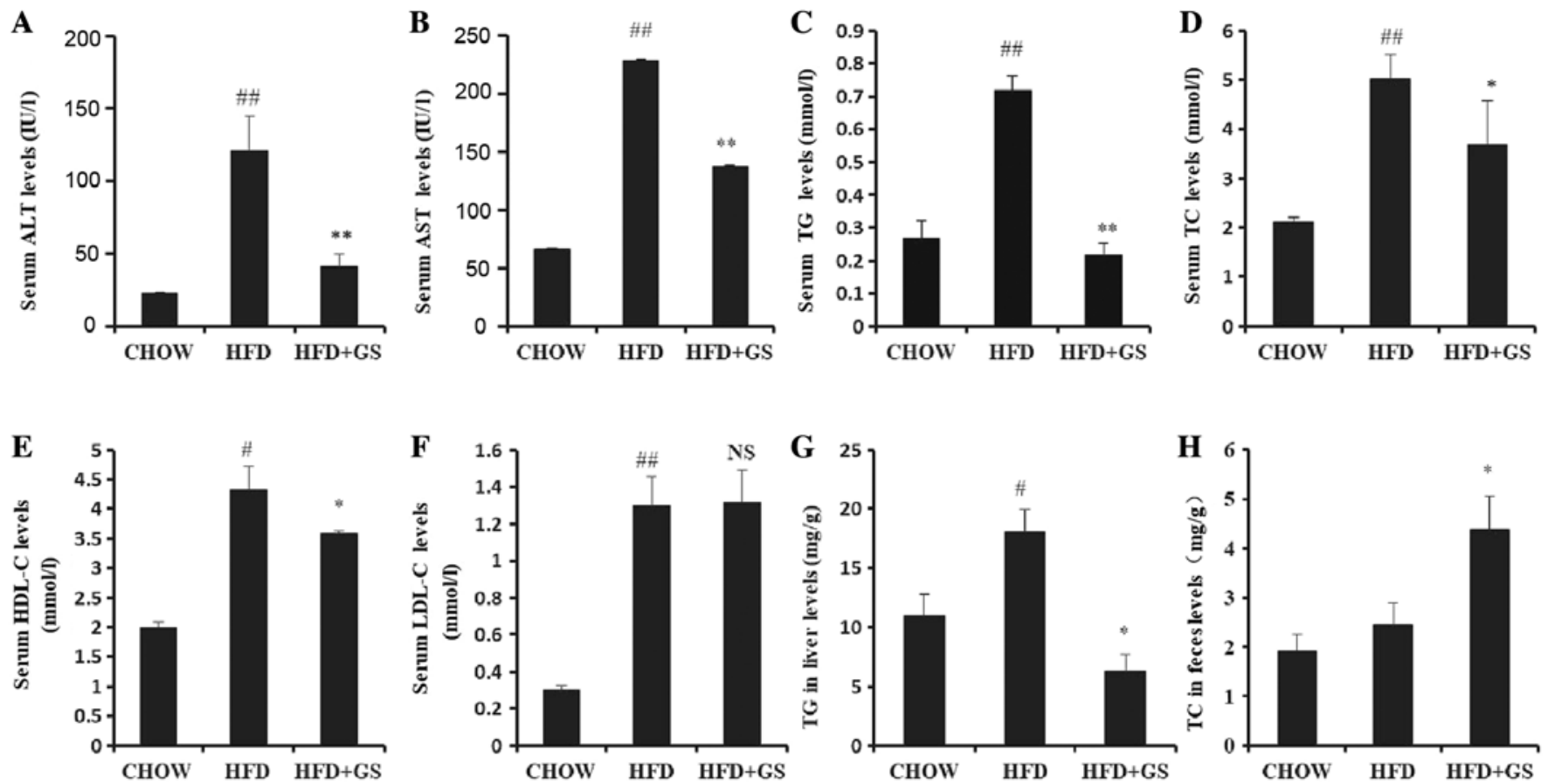

Figure 3. GS improve the lipid metabolism of HFD-fed mice. (A) Serum ALT, (B) serum AST, (C) serum TG, (D) serum TC, (E) serum HDL-c, (F) serum LDL-c, $(\mathrm{G})$ liver TG levels and $(\mathrm{H})$ feces TG levels. Error bars present the mean \pm standard error of the mean. P-values were determined by one-way ANOVA. ${ }^{*} \mathrm{P}<0.05$ and ${ }^{* *} \mathrm{P}<0.01$. vs. HFD group; ${ }^{*} \mathrm{P}<0.05$ and ${ }^{\# \#} \mathrm{P}<0.01$ vs. CHOW group; $\mathrm{n}=5$ for all groups. GS, ginsenosides; HFD, high-fat diet; $\mathrm{CHOW}$, mice administered a standard chow diet; ALT, alanine aminotransferase; AST, aspartate aminotransferase; TG, triglyceride; TC, total cholesterol; HDL-c, high-density lipoprotein cholesterol; LDL-c, low-density lipoprotein cholesterol; NS, no significance. 
A
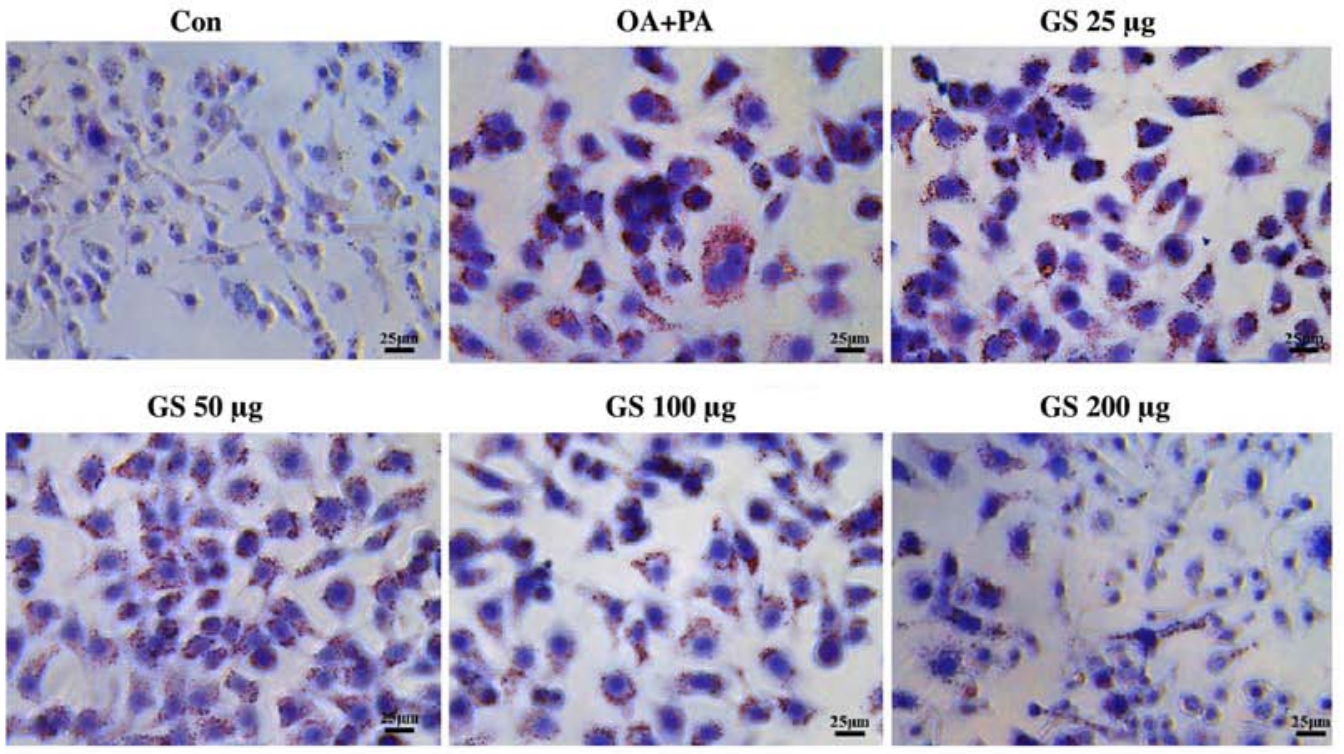

B
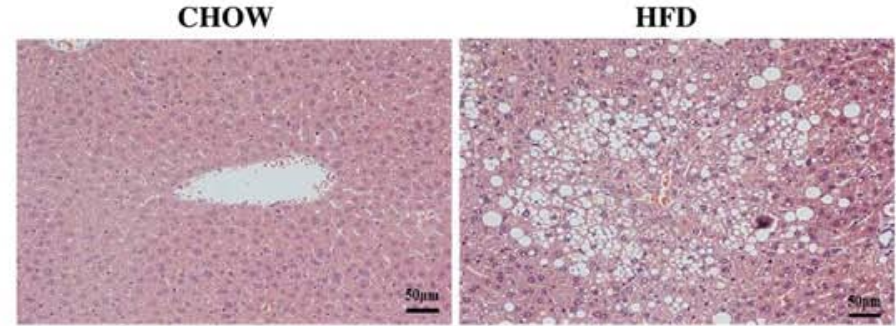

HFD+GS

C
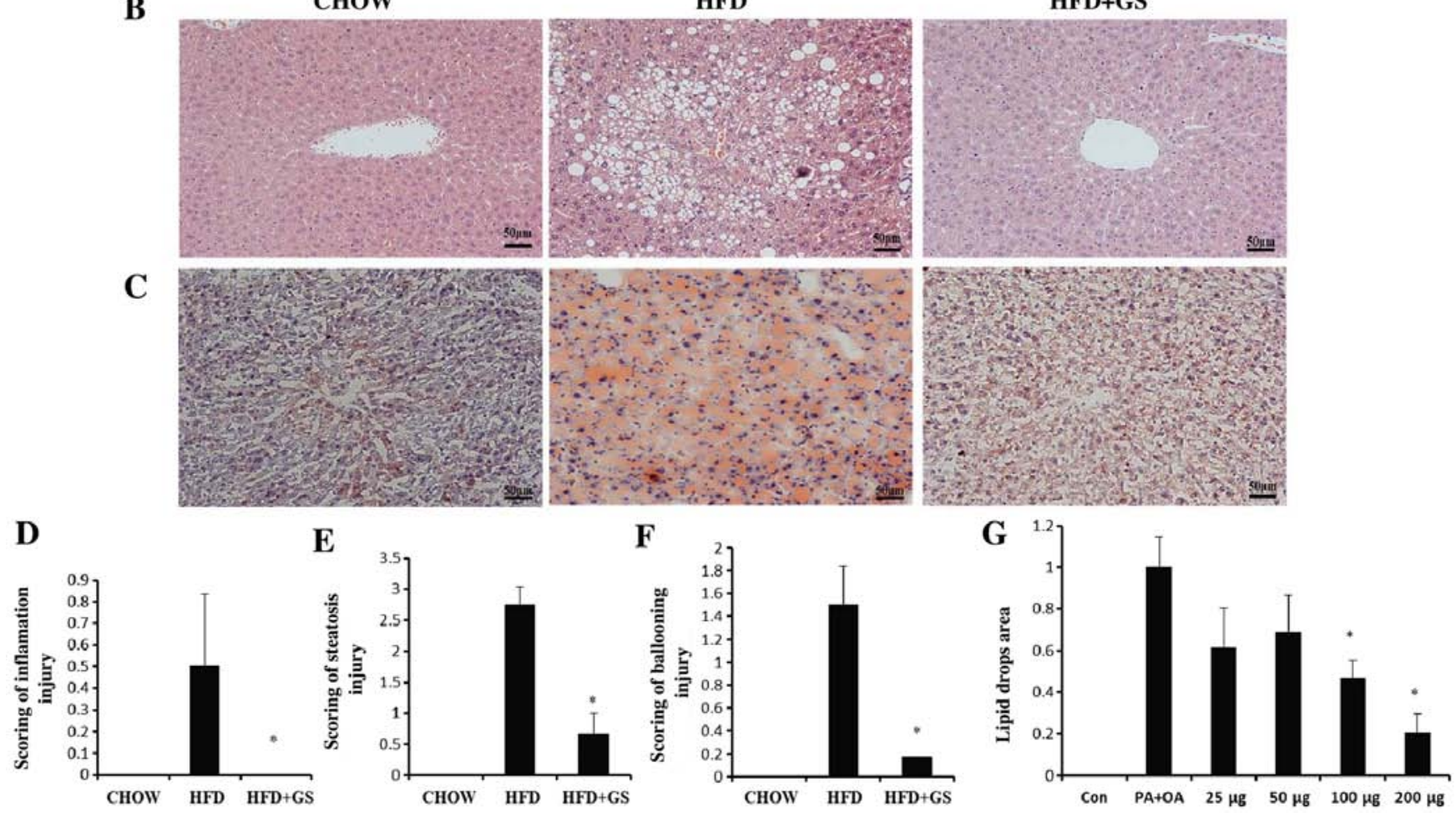

Figure 4. GS alleviates lipid droplet accumulation in vivo and in vitro. (A) Oil red O staining of HepG2 cells (magnification, $\mathrm{x} 400$ ). (B) Hemoxylin and eosin and (C) oil red O staining of liver sections (magnification, x200). Scoring of (D) inflammation injury, (E) steatosis injury and (F) ballooning injury. (G) Lipid accumulation in HepG2 cells. Error bars present the mean \pm standard error of the mean. P-values were determined by a one-way ANOVA. Scale bars, 25 or $50 \mu \mathrm{m}$. " $\mathrm{P}<0.05$, vs. HFD group (D-F); "P<0.05 vs. PA + OA group (G); n=5 for all groups. GS, ginsenosides; HFD, high-fat diet; CHOW, mice administered a standard chow diet; PA, palmitic acid; OA, oleic acid.

of the standard chow diet-fed mice. By contrast, GS treatment efficiently reversed the structural changes and improved the hepatic steatosis (Fig. 4B). In addition, oil red O staining is an important method to observe fat accumulation. The liver sections confirmed that there were few lipids in the livers of the standard chow diet-fed mice, but a massive lipid accumulation in the livers of the HFD mice. GS treatment notably mitigated the lipid accumulation in the livers of the HFD-fed mice (Fig. 4C). Altogether, GS attenuate fatty liver and reduce the diameter of fat cells in HFD-fed mice (Fig. 4D-F; P<0.05).
Effect of GS on metabolic measures. Based on the aforementioned data, it was hypothesized that GS, despite their robust effects on food intake and body weight, also enhance oxygen consumption, carbon dioxide exhalation and result in the utilization of fat as the main energy source. Therefore following metabolic parameters were measured in the HFD-fed mice and HFD+GS group: $\mathrm{VO}_{2}, \mathrm{VCO}_{2}$, RER and X-Amb. The results revealed that the HFD+GS group had significantly increased $\mathrm{VO}_{2}$ and $\mathrm{VCO}_{2}$ compared with the HFD-fed mice (Fig. 5A and $\mathrm{B} ; \mathrm{P}<0.05$ and $\mathrm{P}<0.01$ ). However, as the two 

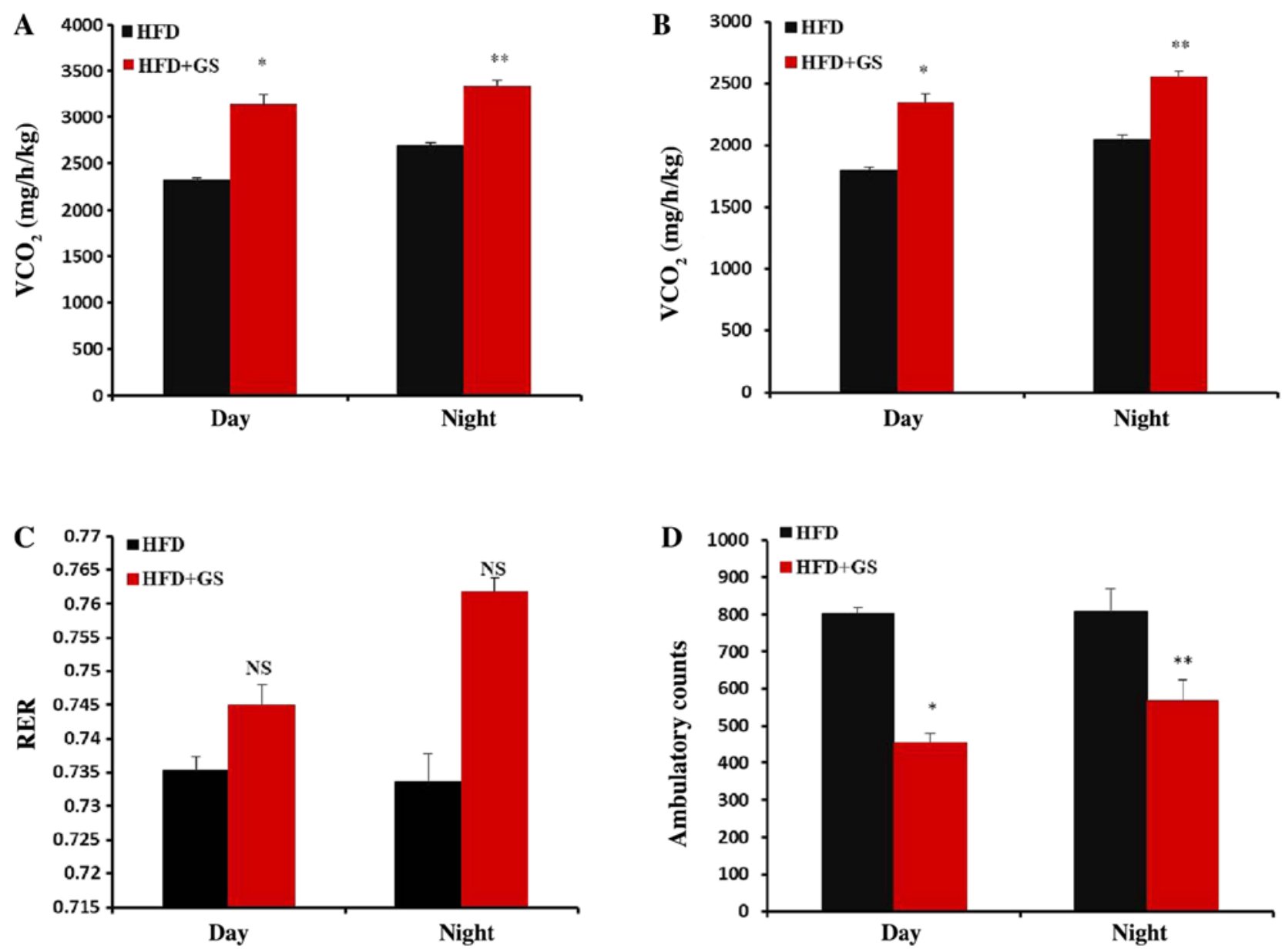

Figure 5. Effect of GS on metabolic measures. (A) Oxygen consumption. (B) Carbon dioxide elimination. (C) RER. (D) Ambulatory count (physical activity). Error bars present the mean \pm standard error of the mean. P-values were determined by a one-way ANOVA. ${ }^{*} \mathrm{P}<0.05,{ }^{* *} \mathrm{P}<0.01$ vs. HFD group; $\mathrm{n}=5$ for all groups. NS, no significance; GS ginsenoside; $\mathrm{HFD}$, high-fat diet; RER, respiratory exchange ratio; $\mathrm{VCO}_{2}$, carbon dioxide consumption; $\mathrm{VO}_{2}$, oxygen consumption.

parameters increased $\left(\mathrm{VO}_{2}\right.$ and $\left.\mathrm{VCO}_{2}\right)$, their ratio remained relatively constant (Fig. 5C). Notably, the levels of activity were significantly lower in the HFD+GS group compared with the HFD group. (Fig. 5D; $\mathrm{P}<0.05$ and $\mathrm{P}<0.01$ ). There are two potential reasons for this effect. First, previous studies have reported that large doses of GS inhibit the activity of mice $(48,49)$. Second, aside from their appetite, mice exhibit reduced consumption and exercise levels naturally $(50,51)$. In conclusion, GS increase the basal metabolic rate of mice to enhance fat mobilization and thereby reduce weight.

GS improve liver ERS and regulate STAT3 phosphorylation in GT1-7 cells and hypothalamus. Specific markers for intracellular STAT3 signaling, and ERS in the GT1-7 GnRH neuron cell line and the liver tissues were analyzed using immunoblotting as previously described (32). As presented in Fig. 6, GS not only reduced the expression of ERS-associated proteins in GT1-7 cells and the liver (Fig. 6A and B; P<0.05), but also regulated the p-STAT3/STAT3 ratio in GT1-7 and hypothalamus tissue (Fig. 6C and D).

\section{Discussion}

The present study identifies a novel function for GS as a potential weight-reducing medicine based on its function in reducing obesity, nonalcoholic fatty liver disease, hyperleptinemia and insulin resistance. The results of the present study demonstrate that GS alleviate metabolic disorders, including obesity, fatty liver, dyslipidemia and hyperglycemia in mice. Furthermore, GS regulate the expression of p-STAT3 and reduce ERS in GT1-7 cells and the liver. These results reveal that GS reduce weight and ameliorate nonalcoholic fatty liver disease partly by increasing the expression of p-STAT3 and reducing the ERS.

China was the first country globally to use and record ginseng in medical literature. Ginseng has been recorded in Chinese medical literature for $>2,000$ years (51). GS are regarded as the main active ingredient in ginseng, thus becoming the point of focus in research (52). GS have a wide range of pharmacological effects and are extensively used to treat numerous different diseases (53). Examples include in the treatment of neurodegenerative diseases in the nervous system, improvement of memory function and protection of brain tissue (54). In the cardiovascular system, GS reduce arrhythmia, cardiac hypertrophy, myocardial ischemia and myocardial apoptosis (24). In terms of tumor types, they may induce apoptosis, inhibit tumor cell proliferation, regulate signal pathways and regulate immune functions (55). With regards to metabolism, they inhibit the absorption of fatty food in the intestinal tract by reducing the activity of PL or through 
A
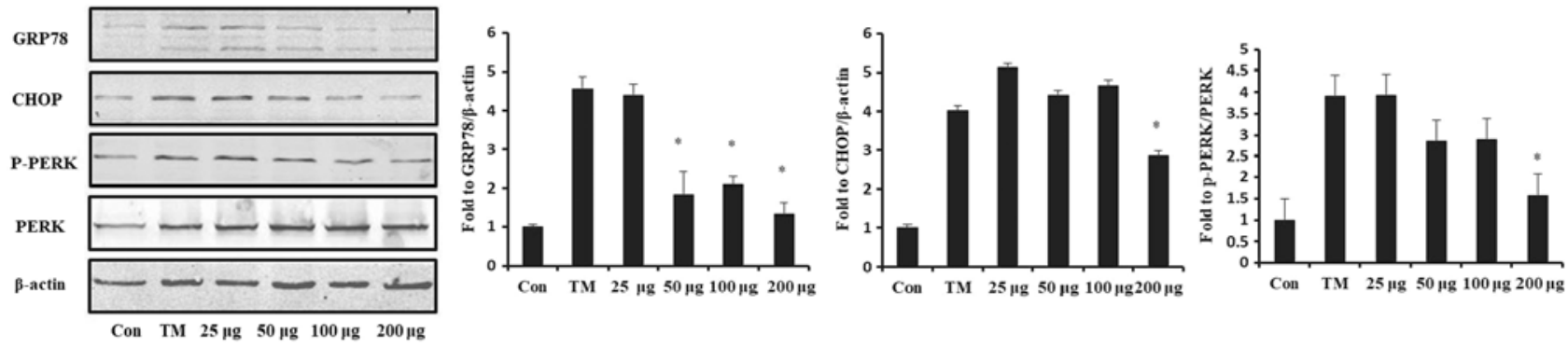

B
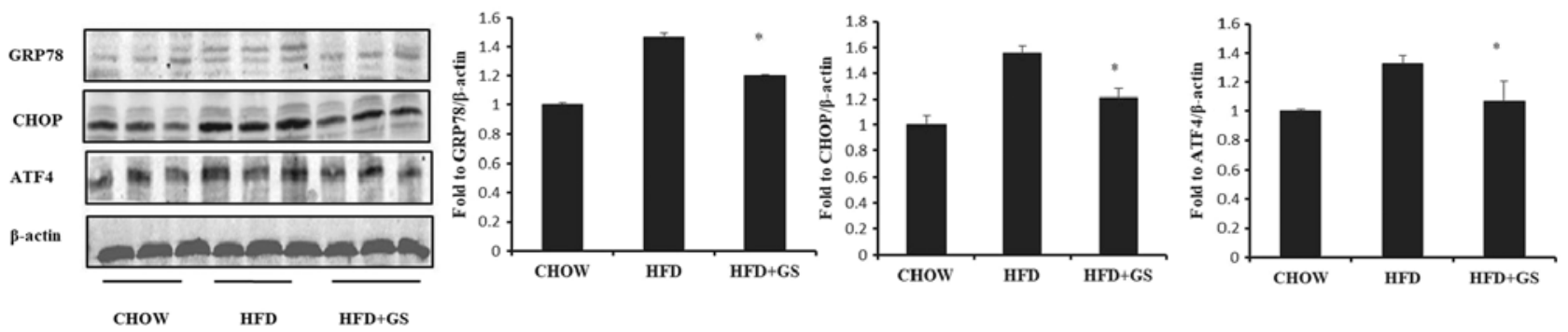

C
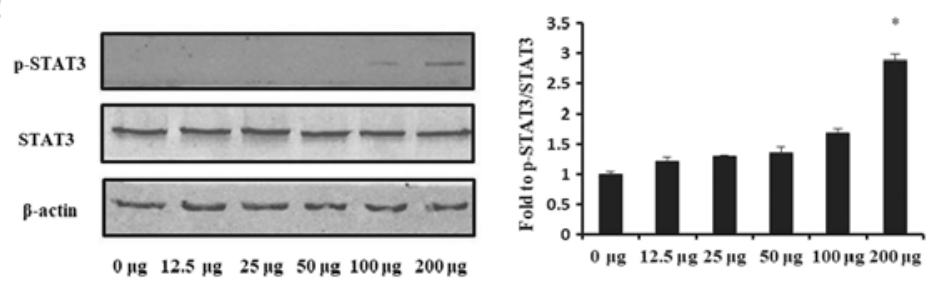

D
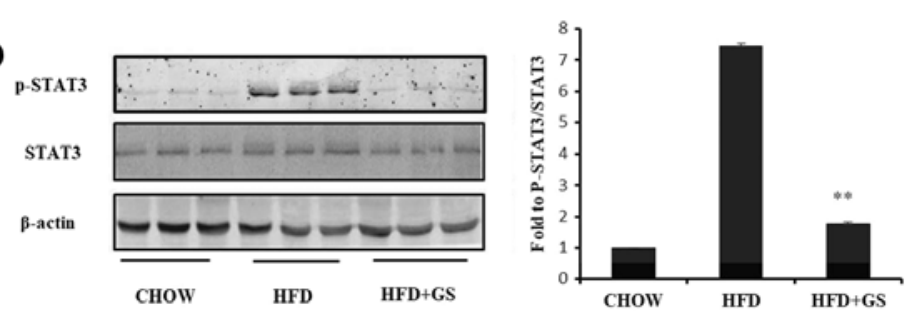

Figure 6. Effect of GS on p-STAT3/STAT3 and ERS. Following treatment for $24 \mathrm{~h}$ (ERS)/12 h (p-STAT3/STAT3), western blotting was performed to determine the relative expression of ERS-associated proteins. (A) Expression of GRP78, CHOP, total PERK and p-PERK in GT1-7 cells treated with $5 \mu \mathrm{g} / \mathrm{ml} \mathrm{TM}$, $5 \mu \mathrm{g} / \mathrm{ml} \mathrm{TM}+25 \mu \mathrm{g} \mathrm{GS}, 5 \mu \mathrm{g} / \mathrm{ml} \mathrm{TM}+50 \mu \mathrm{g} \mathrm{GS}, 5 \mu \mathrm{g} / \mathrm{ml} \mathrm{TM}+100 \mu \mathrm{g} \mathrm{GS}$ or $5 \mu \mathrm{g} / \mathrm{ml} \mathrm{TM}+200 \mu \mathrm{g} \mathrm{GS}$. "P $<0.05 \mathrm{vs}$. TM. (B) Expression of GRP78, CHOP and ATF4 in the liver. ${ }^{*} \mathrm{P}<0.05$ vs. HFD group. (C) Expression of p-STAT3 and total STAT3 in GT1-7 cells treated with GS $(12.5,25,50,100$ and $200 \mu \mathrm{g}) .{ }^{*} \mathrm{P}<0.05$ vs. $0 \mu \mathrm{g}$. (D) Expression of p-STAT3 and total STAT3 in the hypothalamus. ${ }^{* *} \mathrm{P}<0.01$ vs. HFD group. GS, ginsenosides; HFD, high-fat diet; CHOW, mice administered a standard chow diet; STAT3, signal transducer and activator of transcription 3; p-, phosphorylated; ERS, endoplasmic reticulum stress; GRP78, glucose regulation protein 78; CHOP, C/EBP homologous protein; PERK, protein kinase-like endoplasmic reticulum kinase; ATF4, activating transcription factor 4; TM, tunicamycin.

the regulation of the lipogenesis transcription factor PPAR and the glucolipid metabolism regulation molecule AMPK and its target gene expression (56). The compound used in the present study contained up to $80 \%$ GS. Thus, it is rational to propose that GS may be one of the ingredients responsible for the activities of ginseng.

In the present study, the GS treatment reduced the body weight gain induced by HFD and food intake was markedly reduced, indicating that the effect was caused by a reduction in calorie intake (21). The results also revealed that the treatment lowered blood glucose, serum AST, serum ALT, serum TG and liver TG contents and increased the fecal excretion of TG in the mice fed a HFD, suggesting that GS effectively lower HFD-induced hyperglycemia and hyperlipidemia (57).

Decreased food intake may be associated with drug-induced liver injury $(58,59)$. Thus, in the present study, the effect of drug toxicity on the feeding of the HFD-fed mice was investigated extensively. Therefore, H\&E and Oil Red $\mathrm{O}$ staining were performed on the liver tissues to observe the effect of the drug, and the results demonstrated that the reduction of dietary intake was not caused by drug-induced liver injury (60). This was supported by further evidence, including low levels of ALT and AST in the serum (61). In addition, GS reduced lipid accumulation in vivo and in vitro (21). The present results are consistent with previous reports.

Obesity usually causes hyperinsulinemia and hyperleptinemia in the blood circulation, which mainly manifest as reduced glucose tolerance, leptin resistance and dyslipidemia $(62,63)$. Leptin and insulin resistance were induced in mice following 12 weeks on a HFD (64). In the present study, GS administration significantly reduced the levels of circulating insulin and leptin in the HFD-fed mice $(\mathrm{P}<0.05)$. The combination of the results of the glucose tolerance and insulin 
tolerance tests indicate that GS improve leptin and insulin resistance in HFD-fed mice (21).

Previously, an increasing number of studies have demonstrated that leptin resistance was a major cause of obesity (65-67). The important reasons are the regulation of p-STAT3 and increased ERS in the hypothalamus $(68,69)$.

STAT3 is a member of the STAT protein family (70). Leptin receptor is activated by leptin and p-STAT3 (71). Thus, STAT3 is a classical up-regulator of leptin signaling. For example, Liu et al (72) reported that celastrol suppresses appetite, reduces body weight and ameliorates disorders of glucose and lipid metabolism through p-STAT3. Ibars et al (68) reported that proanthocyanidins reduce appetite and weight by increasing phosphorylated STAT3. Interestingly, the present study produced opposing results in vivo and in vitro. The potential reason for this is that there is no ligand of leptin in cells to bind to the leptin receptor, and the effect of increased phosphorylation of STAT3 is all derived from GS. However, in vivo, the excess ligand binding of hyperleptinemia in the serum of obese mice ameliorated the decrease in the receptor ligand binding rate caused by receptor passivation, so the results were inconsistent. In addition, age and other factors would also cause different results (8,73-76).

The endoplasmic reticulum is an extremely active and important organelle in the cell $(76,77)$. It is involved in protein synthesis, storage, processing and modification, and folding (78). Dysfunction of the endoplasmic reticulum results in the accumulation of unfolded or misfolded proteins in the endoplasmic reticulum, which results in ERS (79). There are three mechanisms to survive a stress response in the endoplasmic reticulum: The ATF6 mechanism, the IRE1-splice $\mathrm{X}$-box binding protein 1 mechanism and the PERK-eIF2 mechanism (80). The results of the present study indicate that GS reduce ERS via the PERK-eIF2- $\alpha$ mechanism. For example, Joe et al (81) reported that fibroblast growth factor 21 induced by carbon monoxide mediated metabolic homeostasis via the PERK/ATF4 pathway. Cai et al (82) reported that the alleviation of ERS by aerobic exercise was able to suppress appetite and reduce weight in HFD-fed mice. Wang et al (83) revealed that the alleviation of ERS was able to reduce nonalcoholic fatty liver disease. Furthermore, Fujii et al (84) demonstrated that reducing ERS does reduce nonalcoholic fatty liver disease. Notably, the present study reports that GS significantly reduce ERS through the p-PERK/PERK/ATF4 pathway.

The results of the present study provide evidence that GS serve an important function in weight loss and ameliorating nonalcoholic fatty liver disease in HFD-fed mice. GS also upregulated the phosphorylated protein expression of STAT3 and reduced ERS in vitro and ameliorated nonalcoholic fatty liver disease in vivo. GS may be a novel choice as a highly efficient non-toxic strategy for the treatment of metabolic disorders. The present study still has numerous limitations. Future studies ought to: i) Detect the constituents of total ginsenosides with high-performance liquid chromatography, ii) Observe the feed intake of the obese mice following the injection of GS into the lateral ventricle and iii) Analyze the hypothalamic samples (the dorsomedial hypothalamus, the ventromedial hypothalamus and the arcuate nucleus) using immunostaining with p-STAT3 (Tyr705)-specific antibodies. In conclusion, results from the present study demonstrated that GS reduced weight and improved non-alcoholic fatty liver, and identified possible pathways regulating p-STAT3 and alleviating endoplasmic reticulum stress pathway.

\section{Acknowledgements}

Not applicable.

\section{Funding}

No funding was received.

\section{Availability of data and materials}

All data generated or analyzed during the present study are included in this published article.

\section{Authors' contributions}

Experiment design, operation and writing the manuscript was completed by YY.

\section{Ethics approval and consent to participate}

The present study was conducted in accordance with the ethical standards and according to the Ethical Committee of Shanghai University of Traditional Chinese Medicine (Shanghai, China). The protocols were ethically approved by the Institutional Animal Care and Use Committee of Shanghai University of Traditional Chinese Medicine (approval no. SZY201708002).

\section{Patient consent for publication}

Not applicable.

\section{Competing interests}

The author declares that they have no competing interests.

\section{References}

1. Kinlen D, Cody D and O'Shea D: Complications of obesity. QJM 111: 437-443, 2018.

2. Ahirwar R and Mondal PR: Prevalence of obesity in India: A systematic review. Diabetes Metab Syndr 13: 318-321, 2019.

3. Hu L, Huang X, You C, Li J, Hong K, Li P, Wu Y, Wu Q, Wang Z, Gao R, et al: Prevalence of overweight, obesity, abdominal obesity and obesity-related risk factors in southern China. PLoS One 12: e0183934, 2017.

4. Yilmaz Y and Younossi ZM: Obesity-associated nonalcoholic fatty liver disease. Clin Liver Dis 18: 19-31, 2014.

5. Fruh SM: Obesity: Risk factors, complications, and strategies for sustainable long-term weight management. J Am Assoc Nurse Pract 29 (Suppl 1): S3-S14, 2017.

6. Sáinz N, Barrenetxe J, Moreno-Aliaga MJ and Martínez JA: Leptin resistance and diet-induced obesity: Central and peripheral actions of leptin. Metabolism 64: 35-46, 2015.

7. Eseberri I, Lasa A, Miranda J, Gracia A and Portillo MP: Potential miRNA involvement in the anti-adipogenic effect of resveratrol and its metabolites. PLoS One 12: e0184875, 2017

8. Xu L, Li H, Zhou G, Lu W, Yang R, Liu H and Yang G: DNA-binding activity of STAT3 increased in hypothalamus of DIO mice; the reduction of STAT3 phosphorylation may facilitate leptin signaling. Biochem Biophys Res Commun 505: 229-235, 2018. 
9. Chen Y, Lu W, Jin Z, Yu J and Shi B: Carbenoxolone ameliorates hepatic lipid metabolism and inflammation in obese mice induced by high fat diet via regulating the JAK2/STAT3 signaling pathway. Int Immunopharmacol 74: 105498, 2019.

10. Habib DF, Fahmi AA, Kholousy NM, Amin AI, Shalaby M, Ahmed MM and Shanab AMA: The role of liver in leptin metabolism in experimental nephrotic syndrome. EXCLI J 10: 322-331, 2011.

11. Bergmann TJ and Molinari M: Three branches to rule them all? UPR signaling in response to chemicallyversus misfolded proteins-induced ER stress. Biol Cell 110: 197-204, 2018.

12. Saito A: Physiological functions of endoplasmic reticulum stress transducer OASIS in central nervous system. Anat Sci Int 89: 11-20, 2014.

13. Yilmaz E: Endoplasmic reticulum stress and obesity. Adv Exp Med Biol 960: 261-276, 2017.

14. Ding S, Jiang J, Zhang G, Bu Y, Zhang G and Zhao X: Resveratrol and caloric restriction prevent hepatic steatosis by regulating SIRT1-autophagy pathway and alleviating endoplasmic reticulum stress in high-fat diet-fed rats. PLoS One 12: e0183541, 2017.

15. Kozuka C, Shimizu-Okabe C, Takayama C, Nakano K, Morinaga H, Kinjo A, Fukuda K, Kamei A, Yasuoka A, Kondo T, et al: Marked augmentation of PLGA nanoparticle-induced metabolically beneficial impact of $\mathrm{Y}^{\text {-oryzanol on fuel dyshomeo- }}$ stasis in genetically obese-diabetic ob/ob mice. Drug Deliv 24: 558-568, 2017

16. Abenavoli L, Di Renzo L, Boccuto L, Alwardat N, Gratteri S and De Lorenzo A: Health benefits of Mediterranean diet in nonalcoholic fatty liver disease. Expert Rev Gastroenterol Hepatol 12: 873-881, 2018.

17. Shin J, He M, Liu Y, Paredes S, Villanova L, Brown K, Qiu X, Nabavi N, Mohrin M, Wojnoonski K, et al: SIRT7 represses Myc activity to suppress ER stress and prevent fatty liver disease. Cell Rep 5: 654-665, 2013.

18. Henkel A and Green RM: The unfolded protein response in fatty liver disease. Semin Liver Dis 33: 321-329, 2013.

19. Sozio MS, Liangpunsakul S and Crabb D: The role of lipid metabolism in the pathogenesis of alcoholic and nonalcoholic hepatic steatosis. Semin Liver Dis 30: 378-390, 2010.

20. Zhang Y, Tang C, Tian Y, Yuan H, Gao R and Cao J: Effects of electroacupuncture combined with dietary control on liver endoplasmic reticulum stress in rats with non-alcoholic fatty liver disease. Zhongguo Zhen Jiu 36: 951-956, 2016 (In Chinese)

21. Li Z and Ji GE: Ginseng and obesity. J Ginseng Res 42: 1-8, 2018

22. Shin BK, Kwon SW and Park JH: Chemical diversity of ginseng saponins from Panax ginseng. J Ginseng Res 39: 287-298, 2015.

23. Christensen LP: Chapter 1 Ginsenosides: Chemistry, biosynthesis, analysis, and potential health effects. Adv Food Nutr Res 55: 1-99, 2009.

24. Kim JH: Pharmacological and medical applications of Panax ginseng and ginsenosides: A review for use in cardiovascular diseases. J Ginseng Res 42: 264-269, 2018.

25. Cui ZY, Jo E, Jang HJ, Hwang HI, Lee KB, Yoo HS, Park SJ, Jung MK, Lee YW and Jang IS: Modified ginseng extract induces apoptosis in HepG2 cancer cells by blocking the CXCL8-mediated Akt/Nuclear Factor- $\mathrm{kB}$ signaling pathway. Am J Chin Med 46: 1645-1662, 2018.

26. Lee JB, Yoon SJ, Lee SH, Lee MS, Jung H, Kim TD, Yoon SR Choi I, Kim IS, Chung SW, et al: Ginsenoside Rg3 ameliorated HFD-induced hepatic steatosis through downregulation of STAT5-PPARY. J Endocrinol 235: 223-235, 2017.

27. Etou H, Sakata T, Fujimoto K, Terada K, Yoshimatsu H, Ookuma K, Hayashi T and Arichi S: Ginsenoside-Rb1 as a suppressor in central modulation of feeding in the rat. Nihon Yakurigaku Zasshi 91: 9-15, 1988 (In Japanese).

28. Hurtado-Carneiro V, Sanz C, Roncero I, Vazquez P, Blazquez E and Alvarez E: Glucagon-Like Peptide 1 (GLP-1) can reverse AMP-activated protein kinase (AMPK) and S6 Kinase (P70S6K) activities induced by fluctuations in glucose levels in hypothalamic areas involved in feeding behaviour. Mol Neurobiol 45: 348-361, 2012.

29. Li Z and Ji GE: Ginseng and obesity. J Ginseng Res 42: 1-8, 2018.

30. Wu LX, Xu YY, Yang ZJ and Feng Q: Hydroxytyrosol and olive leaf extract exert cardioprotective effects by inhibiting GRP78 and CHOP expression. J Biomed Res 32: 371-379, 2018.

31. Fan S, Zhang Y, Sun Q, Yu L, Li M, Zheng B, Wu X, Yang B, Li Y and Huang C: Extract of okra lowers blood glucose and serum lipids in high-fat diet-induced obese C57BL/6 mice. J Nutr Biochem 25: 702-709, 2014.
32. Gao J, Bai H, Li Q, Li J, Wan F, Tian M, Li Y, Song Y, Zhang J and Si Y: In vitro investigation of the mechanism underlying the effect of ginsenoside on the proliferation and differentiation of neural stem cells subjected to oxygen-glucose deprivation/reperfusion. Int J Mol Med 41: 353-363, 2018.

33. Luo L, Yin L, Wang D, Zhao Y, Wang Y, Li F, Fang J, Chen H, Fan S and Huang C: Ginkgolide B lowers body weight and ameliorates hepatic steatosis in high-fat diet-induced obese mice correlated with pregnane $\mathrm{X}$ receptor activation. RSC Adv 7: 37858-37866, 2017.

34. Arif A, Terenzi F, Potdar AA, Jia J, Sacks J, China A, Halawani D, Vasu K, Li X, Brown JM, et al: EPRS is a critical mTORC1-S6K1 effector that influences adiposity in mice. Nature 542: 357-361, 2017.

35. Kleiner DE, Brunt EM, Van Natta M, Behling C, Contos MJ, Cummings OW, Ferrell LD, Liu YC, Torbenson MS, Unalp-Arida A, et al: Design and validation of a histological scoring system for nonalcoholic fatty liver disease. Hepatology 41 : 1313-1321, 2005

36. la Fuente FP, Quezada L, Sepúlveda C, Monsalves-Alvarez M, Rodríguez JM, Sacristán C, Chiong M, Llanos M, Espinosa A and Troncoso R: Exercise regulates lipid droplet dynamics in normal and fatty liver. Biochim Biophys Acta Mol Cell Biol Lipids 1864: 158519, 2019.

37. Gerlini R, Berti L, Darr J, Lassi M, Brandmaier S, Fritsche L, Scheid F, Böhm A, Königsrainer A, Grallert H, et al: Glucose tolerance and insulin sensitivity define adipocyte transcriptional programs in human obesity. Mol Metab 18: 42-50, 2018

38. Coccia F, Testa M, Guarisco G, Di Cristofano C, Silecchia G, Leonetti F, Gastaldelli A and Capoccia D: Insulin resistance, but not insulin response, during oral glucose tolerance test (OGTT) is associated to worse histological outcome in obese NAFLD. Nutr Metab Cardiovasc Dis: Aug 10, 2019 doi: 10.1016/j. numecd.2019.08.001 (Epub ahead of print).

39. Rosenzweig T, Skalka N, Rozenberg K, Elyasiyana U, Pinkusb A, Greenb B, Stanevskyb M and Drori E: Red wine and wine pomace reduced the development of insulin resistance and liver steatosis in HFD-fed mice. J Funct Foods 34: 379-389, 2017.

40. Garg N, Thakur S, McMahan CA and Adamo ML: High fat diet induced insulin resistance and glucose intolerance are gender-specific in IGF-1R heterozygous mice. Biochem Biophys Res Commun 413: 476-480, 2011.

41. Loftus TM, Maggs DG and Lane MD: The adipose tissue/central nervous system axis. Diabetologia 40 (Suppl 3): B16-B20, 1997.

42. Svensson AM, Hellerstrom C and Jansson L: Diet-induced obesity and pancreatic islet blood flow in the rat: A preferential increase in islet blood perfusion persists after withdrawal of the diet and normalization of body weight. J Endocrinol 151: 507-511, 1996.

43. Zakrzewska KE, Cusin I, Stricker-Krongrad A, Boss O, Ricquier D, Jeanrenaud B and Rohner-Jeanrenaud F: Induction of obesity and hyperleptinemia by central glucocorticoid infusion in the rat. Diabetes 48: 365-370, 1999.

44. Strader AD, Reizes O, Woods SC, Benoit SC and Seeley RJ: Mice lacking the syndecan-3 gene are resistant to diet-induced obesity. J Clin Invest 114: 1354-1360, 2004.

45. Müller C, Gardemann A, Keilhoff G, Peter D, Wiswedel I and Schild L: Prevention of free fatty acid-induced lipid accumulation, oxidative stress, and cell death in primary hepatocyte cultures by a Gynostemma pentaphyllum extract. Phytomedicine 19: 395-401, 2012

46. Sheng L, Cho KW, Zhou Y, Shen H and Rui L: Lipocalin 13 protein protects against hepatic steatosis by both inhibiting lipogenesis and stimulating fatty acid $\beta$-oxidation. J Biol Chem 286: 38128-38135, 2011.

47. Gao Q, Jia Y, Yang G, Zhang X, Boddu PC, Petersen B Narsingam S, Zhu YJ, Thimmapaya B, Kanwar YS and Reddy JK: PPAR $\alpha$-deficient ob/ob obese mice become more obese and manifest severe hepatic steatosis due to decreased fatty acid oxidation. Am J Pathol 185: 1396-1408, 2015.

48. Takagi K, Saito $H$ and Tsuchiya M: Effect of panax ginseng root on spontaneous movement and exercise in mice. Jpn J Pharmacol 24: 41-48, 1974.

49. Watanabe H, Ohta H, Imamura L, Asakura W, Matoba Y and Matsumoto K: Effect of Panax ginseng on age-related changes in the spontaneous motor activity and dopaminergic nervous system in the rat. Jpn J Pharmacol 55: 51-56, 1991.

50. Lee J, Liu J, Feng X, Salazar Hernández MA, Mucka P, Ibi D, Choi JW and Ozcan U: Withaferin A is a leptin sensitizer with strong antidiabetic properties in mice. Nat Med 22: 1023-1032, 2016 . 
51. Xu Y, Ding J, An JN, Qu YK, Li X, Ma XP, Zhang YM, Dai GJ and Lin N: Effect of the Interaction of Veratrum Nigrum with Panax ginseng on estrogenic activity in vivo and in vitro. Sci Rep 6: 26924, 2016.

52. Zheng M, Xin Y, Li Y, Xu F, Xi X, Guo H, Cui X, Cao H, Zhang $\mathrm{X}$ and Han C: Ginsenosides: A potential neuroprotective agent. Biomed Res Int 2018: 8174345, 2018.

53. Riaz M, Rahman NU, Zia-Ul-Haq M, Jaffar HZE and Manea R: Ginseng: A dietary supplement as immune-modulator in various diseases. Trends Food Sci Technol 83: 12-30, 2019.

54. Kim KH, Lee D, Lee HL, Kim CE, Jung K and Kang KS: Beneficial effects of Panax ginseng for the treatment and prevention of neurodegenerative diseases: Past findings and future directions. J Ginseng Res 42: 239-247, 2018.

55. Chen T, Li B, Qiu Y, Qiu Z and Qu P: Functional mechanism of Ginsenosides on tumor growth and metastasis. Saudi J Biol Sci 25: 917-922, 2018.

56. Kim JH, Yi YS, Kim MY and Cho JY: Role of ginsenosides, the main active components of Panax ginseng, in inflammatory responses and diseases. J Ginseng Res 41: 435-443, 2017.

57. Zhang L, Virgous C and Si H: Ginseng and obesity: Observations and understanding in cultured cells, animals and humans. J Nutr Biochem 44: 1-10, 2017.

58. Majumdar SK, Shaw GK, O'Gorman P and Thomson AD: The effect of naftidrofuryl on ethanol-induced liver damage in chronic alcoholic patients. Drug Alcohol Depend 10: 135-142, 1982.

59. Musialik J, Suchecka W, Klimacka-Nawrot E, Petelenz M, Hartman M and Błońska-Fajfrowska B: Taste and appetite disorders of chronic hepatitis C patients. Eur J Gastroenterol Hepatol 24: 1400-1405, 2012.

60. Kim HG, Jang SS, Lee JS, Kim HS and Son CG: Panax ginseng Meyer prevents radiation-induced liver injury via modulation of oxidative stress and apoptosis. J Ginseng Res 41: 159-168, 2017.

61. Niranjana Murthy H, Dandin VS and Yoeup Paek K: Hepatoprotective activity of ginsenosides from Panax ginseng adventitious roots against carbon tetrachloride treated hepatic injury in rats. J Ethnopharmacol 158: 442-446, 2014.

62. Chen W, Balland E and Cowley MA: Hypothalamic insulin resistance in obesity: Effects on glucose homeostasis. Neuroendocrinology 104: 364-381, 2017.

63. Hofmann A, Peitzsch M, Brunssen C, Mittag J, Jannasch A, Frenzel A, Brown N, Weldon SM, Eisenhofer G, Bornstein SR and Morawietz $\mathrm{H}$ : Elevated steroid hormone production in the $\mathrm{db} / \mathrm{db}$ mouse model of obesity and type 2 diabetes. Horm Metab Res 49: 43-49, 2017.

64. Chen HJ and Liu J: Actein ameliorates hepatic steatosis and fibrosis in high fat diet-induced NAFLD by regulation of insulin and leptin resistant. Biomed Pharmacother 97: 1386-1396, 2018.

65. Crujeiras AB, Carreira MC, Cabia B, Andrade S, Amil M and Casanueva FF: Leptin resistance in obesity: An epigenetic landscape. Life Sci 140: 57-63, 2015.

66. Adam CL and Findlay PA: Decreased blood-brain leptin transfer in an ovine model of obesity and weight loss: Resolving the cause of leptin resistance. Int J Obes (Lond) 34: 980-988, 2010.

67. Myers MG Jr, Leibel RL, Seeley RJ and Schwartz MW: Obesity and leptin resistance: Distinguishing cause from effect. Trends Endocrinol Metab 21: 643-651, 2010.

68. Ibars M, Ardid-Ruiz A, Suárez M, Muguerza B, Bladé C and Aragonès G: Proanthocyanidins potentiate hypothalamic leptin/STAT3 signalling and Pomc gene expression in rats with diet-induced obesity signalling. Int J Obes (Lond) 41: 129-136, 2017.
69. Contreras C, Fondevila MF and López M: Hypothalamic GRP78, a new target against obesity? Adipocyte 7: 63-66, 2018.

70. Raptis L, Arulanandam R, Geletu M and Turkson J: The R(h) oads to Stat3: Stat3 activation by the Rho GTPases. Exp Cell Res 317: 1787-1795, 2011.

71. Koga S, Kojima A, Ishikawa C, Kuwabara S, Arai K and Yoshiyama Y: Effects of diet-induced obesity and voluntary exercise in a tauopathy mouse model: Implications of persistent hyperleptinemia and enhanced astrocytic leptin receptor expression. Neurobiol Dis 71: 180-192, 2014.

72. Liu J, Lee J, Salazar Hernandez MA, Mazitschek R and Ozcan U: Treatment of Obesity with Celastrol. Cell 161: 999-1011, 2015.

73. Sahin-Efe A, Polyzos SA, Dincer F, Zaichenko L, McGovern R, Schneider B and Mantzoros CS: Intracellular leptin signaling following effective weight loss. Metabolism 64: 888-895, 2015.

74. Scarpace PJ, Matheny M and Shek EW: Impaired leptin signal transduction with age-related obesity. Neuropharmacology 39 : 1872-1879, 2000

75. Scarpace PJ and Tümer N: Peripheral and hypothalamic leptin resistance with age-related obesity. Physiol Behav 74: 721-727, 2001.

76. Scarpace PJ, Matheny M and Tümer N: Hypothalamic leptin resistance is associated with impaired leptin signal transduction in aged obese rats. Neuroscience 104: 1111-1117, 2001.

77. Oakes SA and Papa FR: The role of endoplasmic reticulum stress in human pathology. Annu Rev Pathol 10: 173-194, 2015.

78. Schwarz DS and Blower MD: The endoplasmic reticulum: Structure, function and response to cellular signaling. Cell Mol Life Sci 73: 79-94, 2016.

79. Ye Z, Liu G, Guo J and Su Z: Hypothalamic endoplasmic reticulum stress as a key mediator of obesity-induced leptin resistance. Obes Rev 19: 770-785, 2018.

80. Tsuchiya Y, Saito M and Kohno K: Pathogenic mechanism of diabetes development due to dysfunction of unfolded protein response. Yakugaku Zasshi 136: 817-825, 2016 (In Japanese).

81. Joe Y, Kim S, Kim HJ, Park J, Chen Y, Park HJ, Jekal SJ, Ryter SW, Kim UH and Chung HT: FGF21 induced by carbon monoxide mediates metabolic homeostasisviathe PERK/ATF4 pathway. FASEB J 32: 2630-2643, 2018.

82. Cai M, Wang H, Li JJ, Zhang YL, Xin L, Li F and Lou SJ: The signaling mechanisms of hippocampal endoplasmic reticulum stress affecting neuronal plasticity-related protein levels in high fat diet-induced obese rats and the regulation of aerobic exercise. Brain Behav Immun 57: 347-359, 2016.

83. Wang D, Lao L, Pang X, Qiao Q, Pang L, Feng Z, Bai F, Sun X, Lin X and Wei J: Asiatic acid from Potentilla chinensis alleviates non-alcoholic fatty liver by regulating endoplasmic reticulum stress and lipid metabolism. Int Immunopharmacol 65: 256-267, 2018.

84. Fujii J, Homma T, Kobayashi S and Seo HG: Mutual interaction between oxidative stress and endoplasmic reticulum stress in the pathogenesis of diseases specifically focusing on non-alcoholic fatty liver disease. World J Biol Chem 9: 1-15, 2018.

This work is licensed under a Creative Commons Attribution-NonCommercial-NoDerivatives 4.0 International (CC BY-NC-ND 4.0) License. 